\title{
Neural and visceral xanthomatosis in adults
}

\author{
A. A. MILLER AND F. RAMSDEN \\ From the Group Laboratory, Royal Infirmary, Preston
}

SYNOPSIS The clinical, pathological, and chemical findings in a fatal case of generalized HandSchüller-Christian disease in a man of 33 years are presented in case 1 . The necropsy examination revealed granulomatous infiltration of the infra-orbital fat, the pituitary stalk, and the posterior lobe of the pituitary and also of the skull bones and the thyroid cartilage. The spinal dura mater contained multiple xanthomatous deposits which had produced degenerative changes in the cord substance by epidural compression. Interesting features were the tumour-like enlargement of the right heart, massive pancreatic and renal infiltration, also heavy constricting xanthomatous mantles which had produced compression of both kidneys and adrenal glands.

Case 2 is an example of xanthomatous granuloma, confined to the lungs, in a man of 57 years, and not associated with diabetes insipidus. The histological appearances were those of long-standing chronic xanthoma with marked cystic changes in the lungs, dilated bronchioles, and thick-walled stenosed pulmonary arteries.

The pathogenesis of Hand-Schüller-Christian disease is briefly discussed.

It now seems obvious that the classical diagnostic triad of exophthalmos, diabetes insipidus, and bony defects of the calvarium represent only part of the story of Hand-Schüller-Christian disease. Careful study of necropsy material, together with histochemical and chemical examination of the various organs involved, has shown that there are protean manifestations of xanthomatosis. The considerable amount of work carried out on this topic has led to a better understanding of the pathological changes and evolution of the disease process but has not yet determined the cause of the disorder.

The main feature of the disease is the production of granulomata which, in their manner of infiltration, sometimes mimic malignant growths. These lesions appear to arise as a reaction of the reticuloendothelial cells to a stimulus which had not yet been identified in the normocholesterolaemic type. The clinical findings depend upon the various lesions replacing normal functional tissue or causing pressure and displacement by virtue of their size and consistency. Histologically the lesions can usually be differentiated into four phases of a continuum:

1 A proliferative phase when reticulum cells and histiocytes accumulate in the tissues.

2 A granulation phase when there are numerous eosinophils, leucocytes, and giant cells.

Received for publication 23 December 1964.
3 A xanthomatous phase when the cytoplasm of the reticulum cells accumulates lipid; eventually the cytoplasm appears foamy and the 'xanthoma cell' appearance is produced.

4 A fibrous phase when the xanthoma and other cells are replaced by fibroblasts and connective tissue.

The first case presented here is a man aged 33 years who, in addition to the classical features, showed multiple lesions of the spinal dura mater with cord compression, tumour-like infiltration of the heart and pancreas, massive involvement of the kidneys and adrenals, and granulomatous replacement of the thyroid cartilage. Between them the various lesions in this case exhibited all the histological phases seen in Hand-Schüller-Christian disease.

The second case is an example of xanthomatous or eosinophilic granuloma (histiocytosis X) in a man of 57 years; the lesion was confined to the lungs. There was no evidence of diabetes insipidus and no history of pneumothorax.

CASE 1

CLINICAL HISTORY The patient, aged 29 years, was admitted to hospital in early 1958 with a four-week history of vomiting slimy, bile-stained material after breakfast: during the remainder of the day he experienced nausea after meals but this had diminished recently. He worked at an ordnance factory and the vomiting started 
when he was put on powder mixing, but this work only lasted for three weeks. On physical and radiological examination nothing at all abnormal was found with the exception of loss of $12 \mathrm{lb}$. body weight in the last four months. The disorder was regarded as functional and treated with alkalis and sedation was given.

Some eight months later the patient was readmitted with a four-month history of eye trouble. This had started with a pink discharge, the eyelids being adherent in the mornings. The disorder cleared up in about four days but returned with a persistent watery discharge. Two months later his eyes were swollen and prominent but there was no pain.

Examination showed exophthalmos which was more marked on the right than the left side: palpebral fissures were only slightly widened and there was no lid lag. There was no evidence of halo production, squint, diplopia, or tremor: corneal reflexes were positive. Lateral eye movements were equally diminished on both sides. The fundi and vitreous were clear. The right disc was clear and white without papilloedema: the left disc was dark, showing large dilated arterioles and venules, but without exudate or haemorrhage.

There was no evidence of thyrotoxicosis or hypertension and the remainder of the physical examination did not show any abnormality.

INVESTIGATIONS The cerebrospinal fluid was completely normal. Wassermann and other tests for syphilis were negative. Blood chemistry was normal: total and free cholesterol were within normal limits. Blood counts were within normal limits: the erythrocyte sedimentation rate was $22 \mathrm{~mm}$. in the first hour (Wintrobe).

Radiological examination of the skull showed extensive bony defects in the orbital ridges, the parietal bones of both sides, and in the lesser wings of the sphenoid process: other bones of the body were not examined. The radiological appearances were consistent with xanthomatous bone lesions.

A diagnosis of exophthalmic ophthalmoplegia was made.

About one year later the patient was readmitted. The exophthalmos was more marked; there was loss of visual acuity and central scotoma in the left eye (right $=$ N.5, left $=$ N.36). Shortly after admission a left orbital decompression was performed and fibrous tissue (10 g.) was removed from the orbit: two weeks later a further mass of material was removed. In each case histological examination of the material showed the appearances of sclerosing xanthoma of the orbit. Complete blindness in both eyes followed within a few weeks. The patient died suddenly about a month later.

The total period between the first symptoms and death was just over four years but the patient was not under continuous supervision for the last few weeks of this period. The investigations carried out in 1961 were incomplete: the urine specimens were not examined and blood sugar estimations were not carried out.

Necropsy was performed about 24 hours after death. The notable external findings were obesity and marked protrusion of the eyes. The immediate cause of death was post-influenzal pneumonia.

\section{MACROSCOPICAL EXAMINATION OF TISSUES AND ORGANS}

EYES AND ORBITAL REGIONS Retrobulbar fibrous masses arising from the roof and upper margins of the orbits had caused marked proptosis with bilateral loss of palpebral fissures. The mass on the right side was adherent to the nasal bone; the eyeball was displaced downwards and outwards. The mass on the left side had produced perforation and fragmentation of the orbital plate of the frontal bone.

The granulomatous masses, smooth and fibrous with yellowish streaks, filled the backs of the orbital cavities. They surrounded, but did not infiltrate, the distal parts of the optic nerves: there was no direct extra-orbital extension. These retrobulbar accumulations, by producing proptosis, had stretched the nerves and caused blindness.

The frontal bones, including the supraorbital ridges and the other bones forming the orbit, were softer than normal.

CALVARIUM Areas of the vault and base of the skull were softer and thinner than normal, the changes being most marked in the frontal bone and the left parietal region.

BRAIN The cerebral leptomeninges were congested: the cerebral dura and dural sinuses appeared normal. There was no obvious lesion on the external surfaces of the cerebrum, brain-stem, or cerebellum. The optic chiasma and optic nerves up to the optic foramina appeared normal, as did all the other cranial nerves. Coronal sections throughout the brain did not reveal any abnormality.

PITUITARY GLAND AND STALK The diaphragma sellae appeared thickened and fibrosed: the pituitary stalk was swollen, dark in colour, and bore multiple small yellow nodules: the body of the gland appeared normal. The tuber cinereum appeared normal.

SPINAL CORD AND SPINAL DURA Numerous raised, rounded and ovoid nodules and plaques were present on the extradural surfaces: they were yellow, had a rubbery consistency, and their diameters varied between 5 and $20 \mathrm{~mm}$. These lesions were found mainly on the right lateral aspect of the cervical region and the left lateral aspect of the midthoracic and upper lumbar regions: they were firmly adherent to and probably infiltrating the dura (Fig. 1).

RESPIRATORY SYSTEM AND ASSOCIATED STRUCTURES The mucosa from the nasopharynx down into the bronchial branches was intensely congested. The 


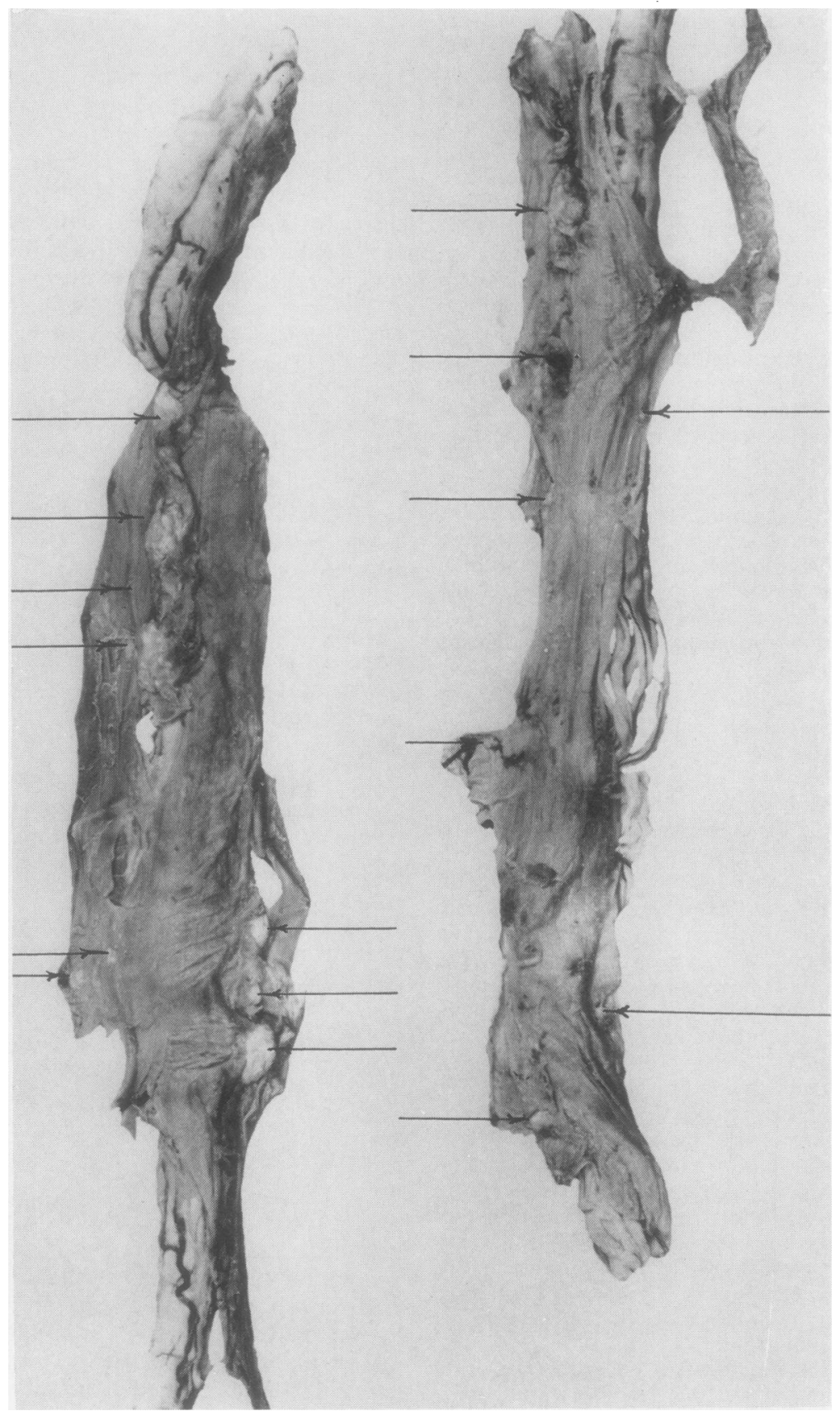

FIG. 1. Case 1. The spinal cord showing many extradural xanthomatous nodules. 
pleural cavities were empty but all pleural surfaces were intensely congested and haemorrhagic. Both lungs were enlarged and showed the appearances of haemorrhagic post-influenzal pneumonia. A few enlarged lymph nodes were found in the mediastinum near the trachea.

The hyoid bone, epiglottis, and tracheal cartilages appeared normal: the whole of the thyroid cartilage was soft and pliable. The thyroid gland appeared normal.

Apart from the lesion in the thyroid cartilage there was no evidence of granuloma in the respiratory system and associated structures.

CARDIOVASCULAR SYSTEM The heart and pericardium weighed $385 \mathrm{~g}$. and there was no evidence of coronary artery disease.

On the visceral pericardium there were numerous raised, rounded and ovoid nodules and yellow plaques. The lesions were mainly at the base of the heart and around the great vessels, mostly on the right side. These nodules, which showed considerable variation in size, were usually in clusters but some were solitary. The largest single nodule $(5 \times 2 \mathrm{~cm}$.) had replaced the right atrial appendage; from its anterior margin a line of nodules extended downwards to the atrio-ventricular groove. On the ventricular side of the groove large, solid, yellow nodules bulged beneath the pericardium (Fig. 2). Section showed granulomatous infiltration of the subpericardial fat and the full thickness of the myocardium to the immediately subendocardial level (Fig. 3). In the subpericardial plane a diffuse infiltration extended towards the apex for about $5 \mathrm{~cm}$. beyond the area of the nodules. There was some involvement of the chordae tendiniae but the aperture of the tricuspid valve was not obstructed. The other valves and the remainder of the pericardium were not involved.

Lines and clusters of smaller yellow nodules were present in the region of the left atrio-ventricular groove and along the free border of the left atrial appendage. Here the granulomatous infiltration was usually limited to the subpericardial fat but one larger nodule, on the lateral wall of the ventricle, had penetrated the myocardium. Similar nodules were present on the external surface of the thoracic aorta above the level of the semilunar valves.

ABDOMINAL ORGANS The pancreas was enlarged $(250 \mathrm{~g}$.) and firm in consistency. A large fibrous mass $(10 \times 7 \times 4 \mathrm{~cm}$. $)$ had replaced the head, neck, and part of the body of the pancreas: the cut surfaces were grey-white with yellow streaks and patches. On the peritoneal surface there was one large $(2 \times 2 \times 5 \mathrm{~cm}$. $)$ and several smaller nodules. The

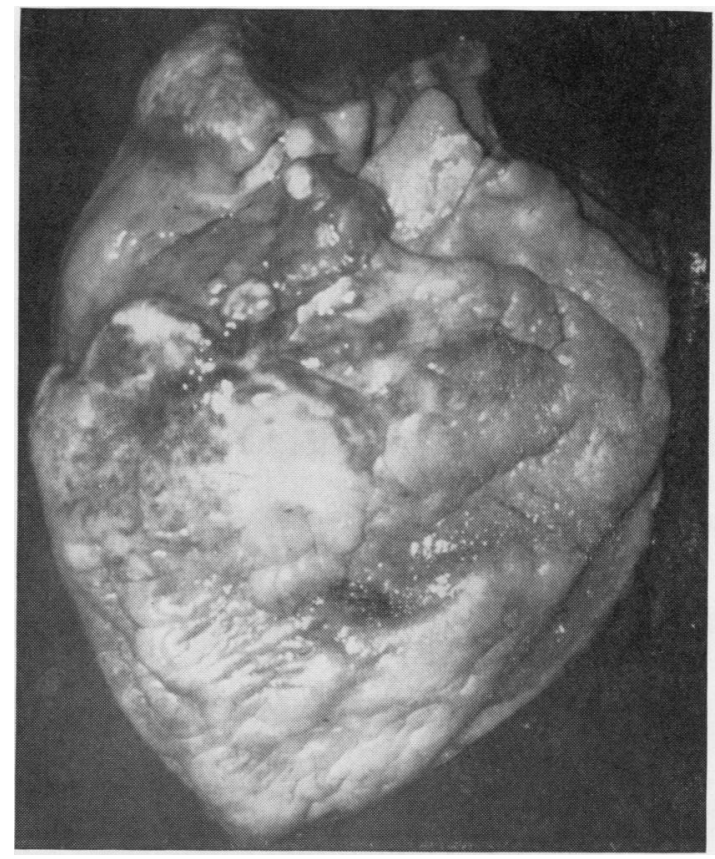

FIG. 2. Case 1. The heart showing multiple subpericardial xanthomatous nodules on the walls of the right auricle and ventricle.

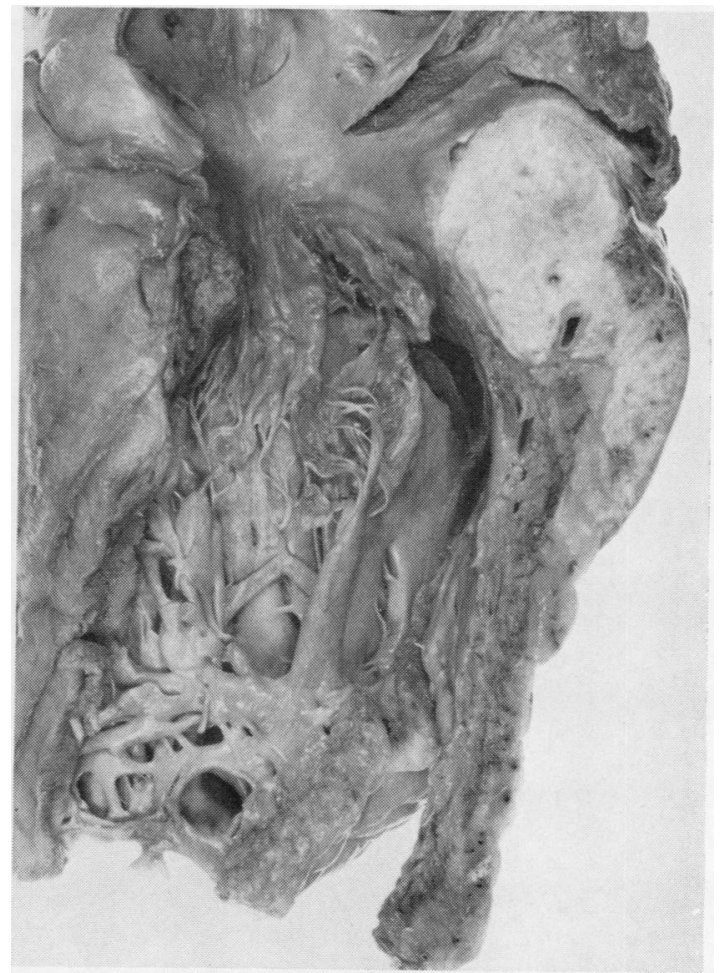

FIG. 3. Case 1. A slice of the right ventricular wall showing extensive infiltration by xanthomatous tissue. 
remainder of the body and tail of the pancreas, together with a thin rim of the head, appeared normal.

The spleen was enlarged with a smooth capsule: the splenic pulp soft and haemorrhagic. There was no evidence of granuloma.

All the other abdominal organs appeared normal.

UROGENITAL SYSTEM AND ADRENAL GLANDS The kidneys and adrenal glands were together encased in mantles of fibro-fatty material varying in thickness between 2.5 and $3 \mathrm{~cm}$., the adrenal glands being seen as narrow, yellow tubular structures $(3 \times 0.3 \mathrm{~cm}$.) above the upper renal poles. The outer rim was unaltered fat; the inner layer, firmly fused to the renal capsule, was firm and largely consisted of xanthomatous material with yellowish, watered silk appearances on the cut surfaces. This mass had also

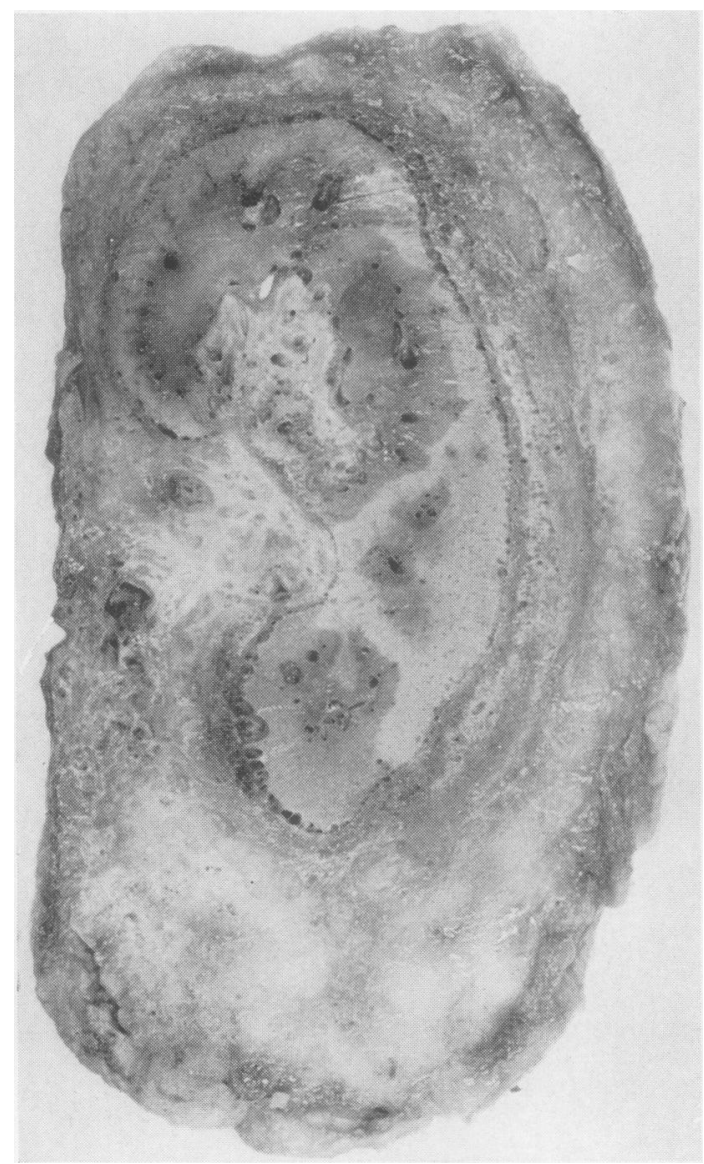

FIG. 4. Case 1. The kidney showing thick perirenal mantle of xanthomatous tissue compressing and infiltrating the substance $\times 2$. surrounded the renal blood vessels and the proximal parts of the ureters (Fig 4).

The xanthomatous masses weighed $240 \mathrm{~g}$. on the right side and $280 \mathrm{~g}$. on the left : the stripped kidneys each weighed $190 \mathrm{~g}$. The ratio of mantles to kidneys was 1.5 to 1.0 by volume.

By its prolonged pressure this solid, strangulating xanthomatous mass had produced a peculiar pattern of indentations on the cortical surfaces of the kidney and adrenal glands. In addition the granulomatous material had infiltrated the renal cortex and pyramids.

The ureters, urinary bladder, and prostate gland appeared normal.

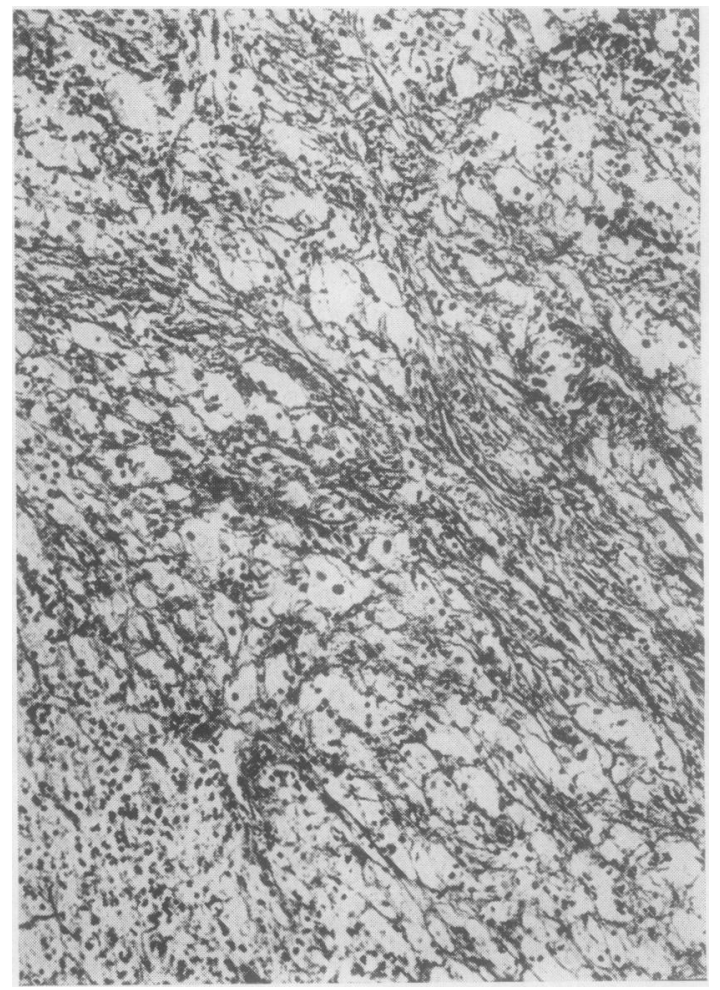

FIG. 5. Case 1. Orbital tumour showing foamy-cell infiltration. Modified Foot's reticulin stain $\times 156$.

MICROSCOPICAL EXAMINATION OF ORGANS AND TISSUES

EYES AND ORBITAL REGIONS The retrobulbar granulomata consisted of collagenous fibrous tissue surrounding islands of large foamy xanthoma cells stuffed with lipid droplets (Fig. 5). There was also diffuse and focal infiltration with histiocytes, lymphocytes, and plasma cells together with occasional multinucleate giant cells. Eosinophils were not seen. 
The eyeballs and associated musculature were not involved.

CALVARIUM In the medullary spaces of the parietal bone the marrow was replaced by a cellular granulomatous mass comprising reticulum cells, histiocytes, and a few eosinophils: some of the spaces contained typical xanthoma cells (Fig. 6). These lesions were more cellular than those in the orbits and contained much less fibrous stroma.

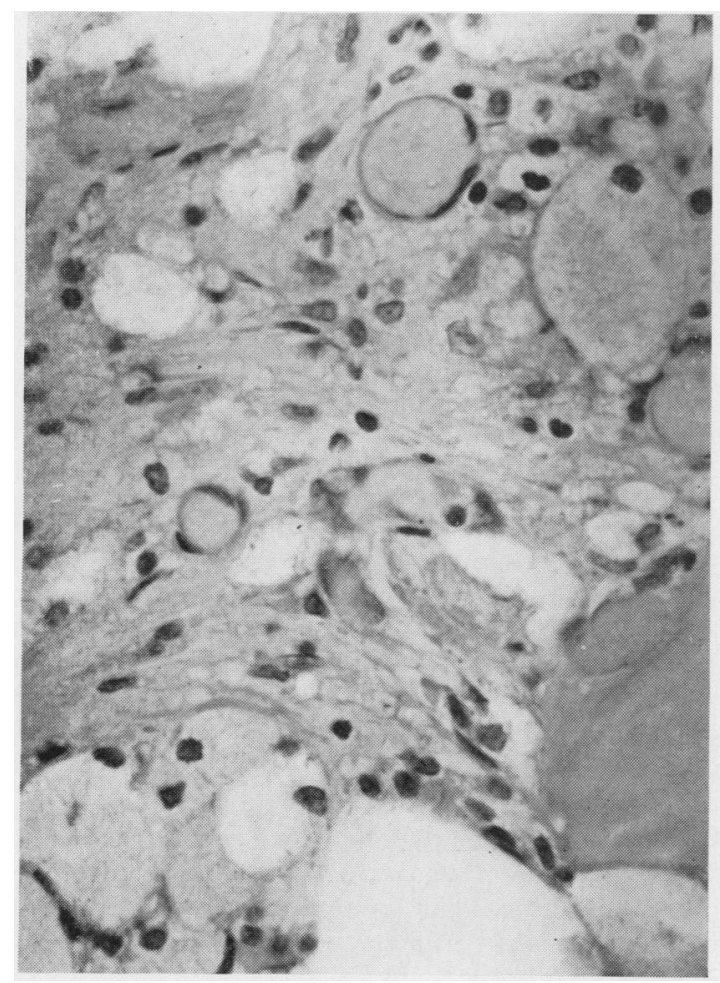

FIG. 6. Case 1. Parietal bone showing collagenous tissue and a few typical foam cells. Haematoxylin and eosin $\times 780$.

BRAIN Granulomatous lesions were not seen in the substance of the cerebrum, brain-stem, or cerebellum: all ependymal linings were smooth. The only abnormal finding was small areas of demyelination in the striate nuclei, internal capsule, thalamus, substantia nigra, pons, cerebellar peduncle, and the cerebellar white matter. They were mainly perivascular in distribution and some of them contained glial cells with pale cytoplasm and deeply stained nuclei; occasional mononuclear giant cells were present but not compound granular corpuscles. The pathological process was mainly patchy degeneration of myelin sheaths with some loss of axis cylinders but in the substantia nigra and some parts of the thalamic nuclei, there was disintegration of the substance.

Of the cranial nerves, the fifth, seventh, and eighth showed marked demyelination whilst the third and ninth showed slight loss only. The full length of the optic nerves was examined: there was almost complete loss of myelin in the nerve heads and in the retrobulbar parts which had been surrounded by xanthoma: in the parts behind the optic foramina and in the chiasma there were smaller areas of demyelination.

PITUITARY GLAND AND STALK The neurohypophysis was atrophied and replaced by fibrous tissue in which fibroblasts, scanty mononuclear cells, and occasional giant cells were seen. Fingers of fibrous tissue extended from the pars posterior into the pars anterior but otherwise the cytology of the adenohypophysis was normal.

The stalk of the pituitary was thickened, collagenous, and contained large foci of typical xanthoma cells.

The tuber cinereum, the floor of the third ventricle, and the mamillary bodies appeared normal.

SPINAL CORD AND DURA In the lumbar region there was granulomatous infiltration of the dura but elsewhere the extradural lesions were well circumscribed, showing sclerosing xanthoma with foci of eosinophilic granuloma (Fig. 7). The fibrous stroma was loose in texture, the xanthoma cells contained sudanophilic material, and the cellular elements included histiocytes, lymphocytes, multinucleate giant cells, and eosinophils.

Changes in the cord substance consisted of demyelination and degeneration of neurones. They were milder in the cervical region, became more marked in the thoracic segments, and were most marked in the lumbo-sacral region.

There was loss of myelin in the lateral and posterior white columns and in an occasional anterior column. Posterior spinal nerve roots showed more or less demyelination at all levels. The ventral nerve roots were slightly affected at the thoracic and lumbo-sacral levels. In the lower lumbar segment there was a circumscribed pale area in a nerve rootlet where epidural compression had led to herniation of neuroglia.

Many of the neurones in the anterior horns and Clark's columns showed chromatolysis, homogenous cytoplasm, and pyknotic nuclei; in a few instances there was loss of the nucleus and atrophy: other neurones were well preserved. These changes were more common in the lower than the upper levels of the cord.

Many of the large ganglion cells of the anterior 


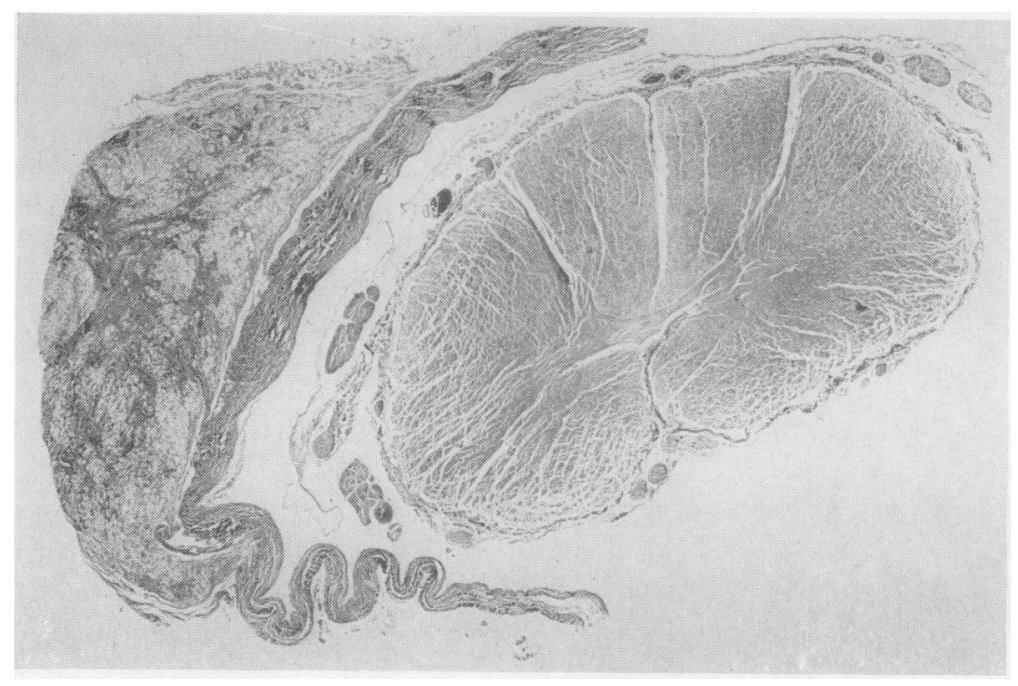

FIG. 7. Case 1. The upper cervical cord with extradural xanthomatous nodule. Van Gieson $\times 7$.

horns, even when the morphology was well preserved, contained deposits of isotropic sudanophilic material. In a few instances degenerate cells were largely represented by clumps of this lipid material.

Histochemical and polarized light examination gave the impression that the lesions were mainly loss of myelin sheaths with axis cylinders well preserved:

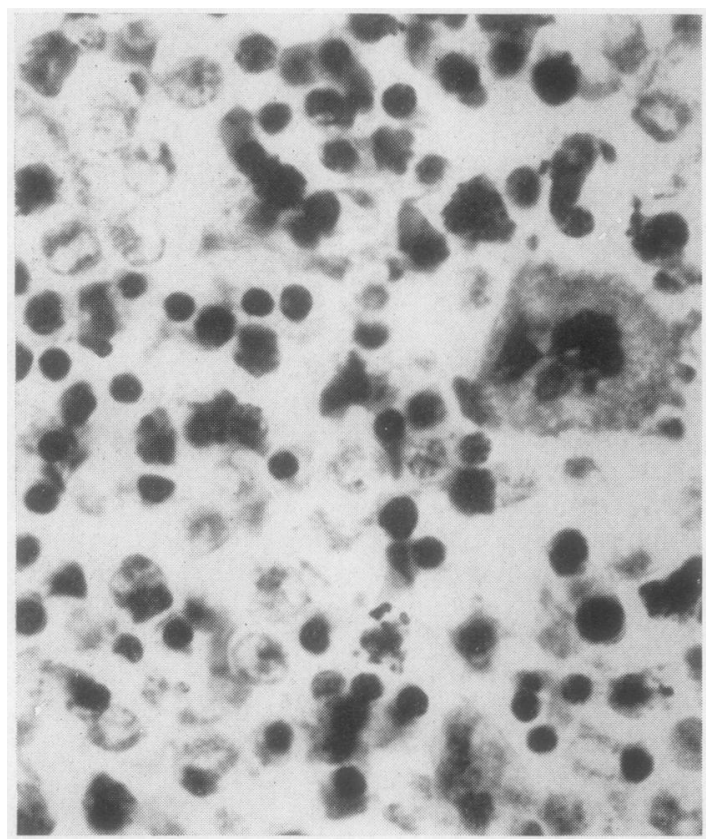

FIG. 8. Case 1. The cellular infiltrate in the thyroid cartilage, including histiocytes and giant cells. Many of the cells contain lipid material. P.T.A.H. $\times 600$. the changes were well marked in the grey columns of the anterior horns as well as in the white columns.

Histiocytes, containing anisotropic lipid material, were seen around small capillaries in grey and white columns and in the spinal nerve roots.

RESPIRATORY SYSTEM AND ASSOCIATED STRUCTURES The central parts of the thyroid cartilage, on both sides, were atrophic and replaced by a cellular granuloma comprising closely packed masses of reticulum cells (Fig. 8) histiocytes, eosinophils, and multinucleate giant cells resembling Touton cells, together with a few lymphocytes and plasma cells. Typical xanthoma cells were not seen but some of the giant cells contained lipid droplets. The residual cartilage on the periphery was irregularly lined by collagenous fibrous tissue.

One of the upper rings of the trachea contained a cellular focus similar to those seen in the thyroid cartilage. There were small foci of histiocytes, lymphocytes, and plasma cells in the laryngeal submucosa.

Of the three peritracheal lymph nodes two showed irritative hyperplasia only; in the third there was fibrous replacement of lymphoid tissue and areas of xanthoma cells.

The thyroid gland appeared normal.

CARDIOVASCULAR SYSTEM The lesions in the heart varied in structure: those in the visceral pericardium and myocardium largely consisted of xanthoma cells; those in the right ventricular wall contained a proportion of spindle cells whilst the lesions in the left ventricular wall were partly collagenous and 
included foci of round cells. The xanthomatous granuloma had largely replaced subpericardial fat and also involved the muscle.

In those parts where muscle fibres were infiltrated or replaced there was usually a predominance of xanthoma cells (Fig. 9): these cells contained anisotropic, sudanophilic material consisting of cholesterol and its esters (Fig. 10).

ABDOMINAL ORGANS The large mass in the head of the pancreas showed the typical appearances of sclerosing xanthoma with infiltration and replacement of normal parenchyma. Sections from the other nodules in the pancreas showed varying proportions of fibrous and xanthomatous elements, the latter predominating where there was infiltration of superficial fat. Other cell types were minimal and consisted of a few round cells.

UROGENITAL SYSTEM AND ADRENAL GLANDS The perirenal and adrenal mantles consisted of sclerosing xanthoma with numerous cellular foci, including histiocytes, lymphocytes, and plasma cells with a few eosinophils.

The adrenal cortex showed marked retrograde atrophy with destruction of the superficial layers of the cortex: the medulla showed less marked atrophy. There was only slight infiltration of cortex and medulla by xanthoma cells.

The renal pyramids were considerably infiltrated with xanthomatous material along with foci of histiocytes, lymphocytes and occasionally plasma cells: eosinophils were not seen. In some areas there was extension into the cortex (Fig. 11). Where the granuloma impinged upon or infiltrated the cortex tubules and glomeruli had markedly atrophied.

\section{CHEMICAL EXAMINATION OF TISSUE}

Samples of the formalin-fixed tissues were taken from various sites, the differentiation between normal and abnormal material being made by macroscopical examination. Each sample was finally divided, mixed, and separated into two portions, one for determination of moisture content, the other for chemical analysis.

MOISTURE CONTENT Each sample was weighed before and after drying in a vacuum dessicator at room temperature: the drying process was continued to constant weight.

CHEMICAL ANALYSIS Each sample was extracted with chloroform for 24 hours and then for two further 24-hour periods with an alcohol-ether mixture ( $3: 1$ by volume), all the extractions being made at room temperature. The three extracts were pooled and made up to a convenient volume with additional solvent. Suitable aliquots of this solution were evaporated to dryness by warming and

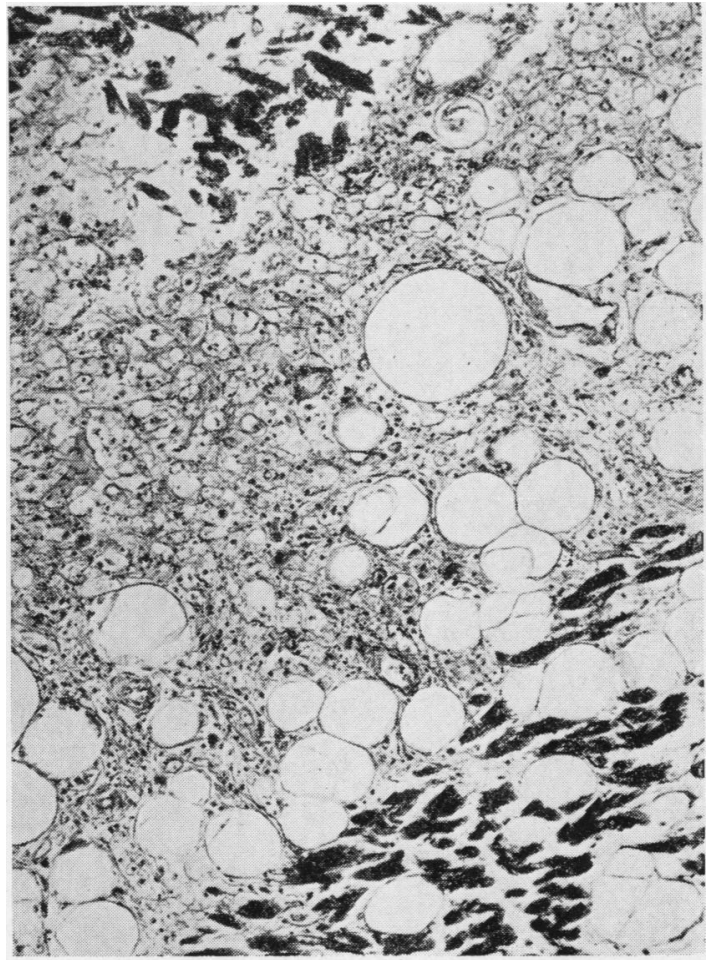

FIG. 9. Case 1. The myocardium of the right ventricle is largely replaced by foamy-cell infiltration. Modified Foot's reticulin stain $\times 100$.

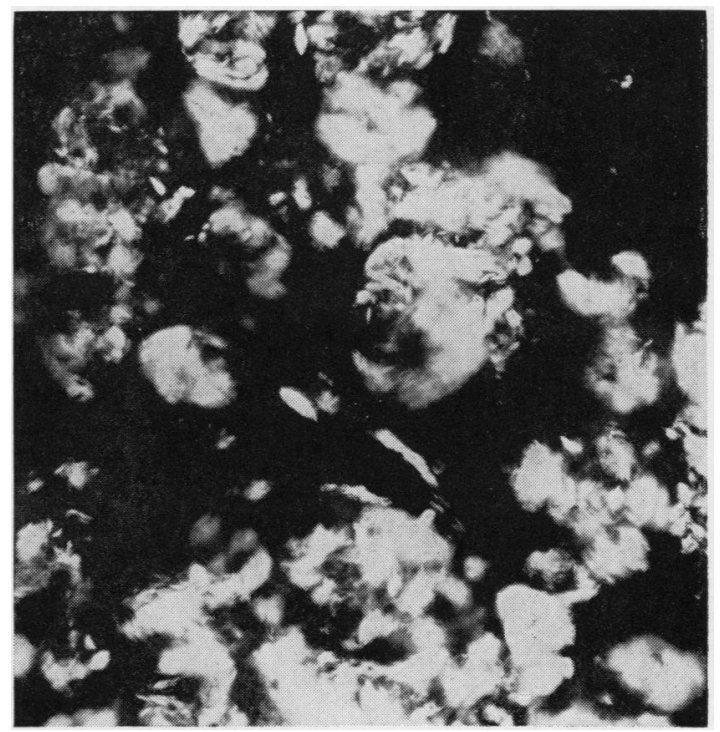

FIG. 10. Case 1. Frozen section of xanthomatous tissue of the heart viewed with the polarizing microscope: crystals of cholesterol esters are present in abundance. Sudan III $\times 400$. 


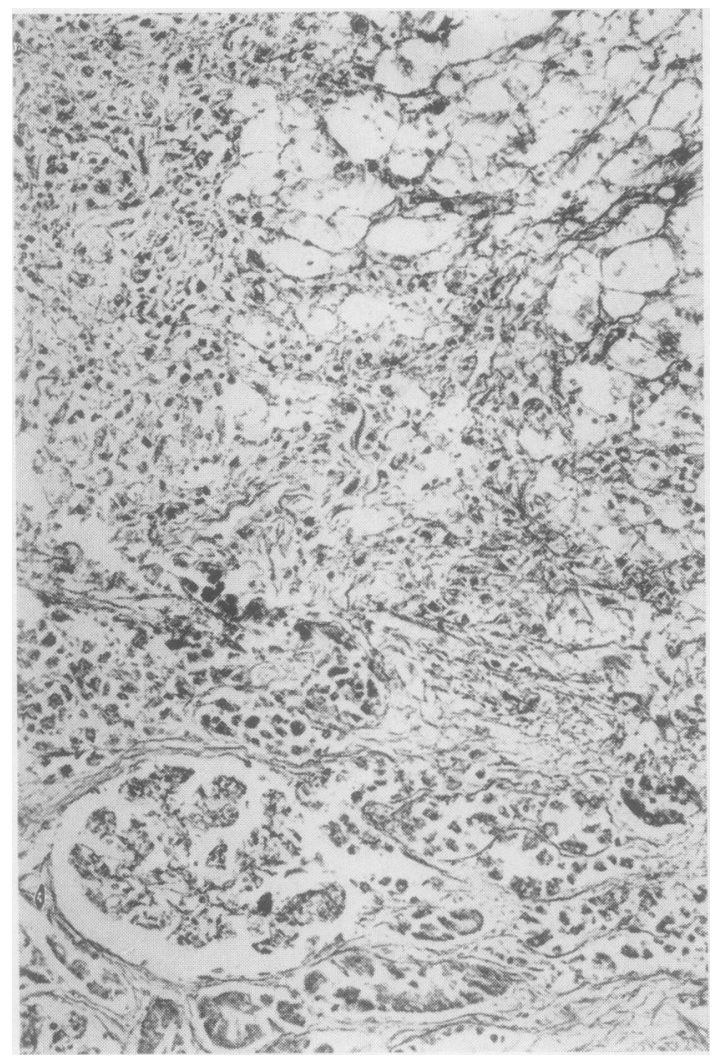

FIG. 11. Case 1. Foamy-cell infiltration of the cortex of the kidney. Modified Foot's reticulin stain $\times 156$.

the residue examined for total cholesterol or total phospholipid.

Total cholesterol was estimated by the method of Pearson, Stern, and McGavack (1953). The phospholipid was converted to phosphate and estimated by the Gomori (1942) method, a phosphate to phospholipid conversion factor of 25 being used in the final calculation. The results of the analyses are explained in the discussion.

CASE 2

CLINICAL HISTORY This man had a long history of chronic bronchitis and suffered pneumonia on two occasions. About one year before death surgery for haemorrhoids and repair of hernia was undertaken. A few months later there was an eczematous skin rash, mainly on the perineum, which responded to topical therapy: there was no suggestion of xanthomatous eruption. Evidence of diabetes insipidus or pneumothorax was not noted. When aged 57 years he complained of feeling unwell and had a severe haemoptysis; death followed within a few hours.

At necropsy, 24 hours after death, the main findings were xanthomatous deposits in both lungs and bronchogenic carcinoma which had caused the fatal haemoptysis.
MACROSCOPICAL EXAMINATION OF TISSUES AND ORGANS

RIGHT LUNG The upper lobe and apex showed tough, grey, fibrous tissue interspersed with cystic air spaces and opaque yellow areas. The middle and lower lobes were intensely congested but without cysts or fibrosis.

LEFT LUNG The lower lobe was replaced by tough grey, fibrous tissue with islands of opaque yellow material: yellow nodules were present on the pulmonary ligament, the posterior border of the base, and on parts of the diaphragmatic surface. The upper lobe was congested.

MEDIASTINUM A massive carcinoma of the right main bronchus had invaded the root of the right lung and slightly infiltrated the substance. The tumour extended from the mid-tracheal level to the base of the heart where the great vessels were surrounded: there was epithelial invasion of the superior vena cava close to the right auricle, the tumour having penetrated the intima and formed a large mass which partly obstructed the lumen. Some of the lymph nodes at the roots of the lungs contained metastatic carcinoma.

OTHER ORGANS Evidence of xanthoma was not found in any organs or tissues other than the lungs.

The right heart was dilated and the ventricular wall thickened: the aorta and coronary arteries were mildly atheromatous. The kidneys showed granularity of the cortical surfaces but were otherwise normal. Apart from scarring of the perineum the skin appeared normal. The brain, pituitary gland and stalk did not show obvious pathology.

\section{MICROSCOPICAL EXAMINATION}

In the left lower and right upper lobes of the lungs there was marked irregular fibrosis and dense cellular infiltration (Fig. 12). The subpeural interlobular, peribronchiolar and perivascular connective tissue showed collagenous thickening and was infiltrated by cellular exudate which included multinucleate macrophages containing carbon pigment, plasma cells, lymphocytes, and a few eosinophils. In frozen sections there were also macrophages which contained sudanophilic material (Fig. 13). In the more deranged areas of the right apex and left base the alveolar walls were disrupted; some of the resultant cytic air spaces were lined by cuboidal and flattened epithelium, others by granulation tissue (Fig. 14). At the left base and along the pleural borders there were numerous islands of foam cells. (Fig. 15).

Respiratory bronchioles were dilated and con- 


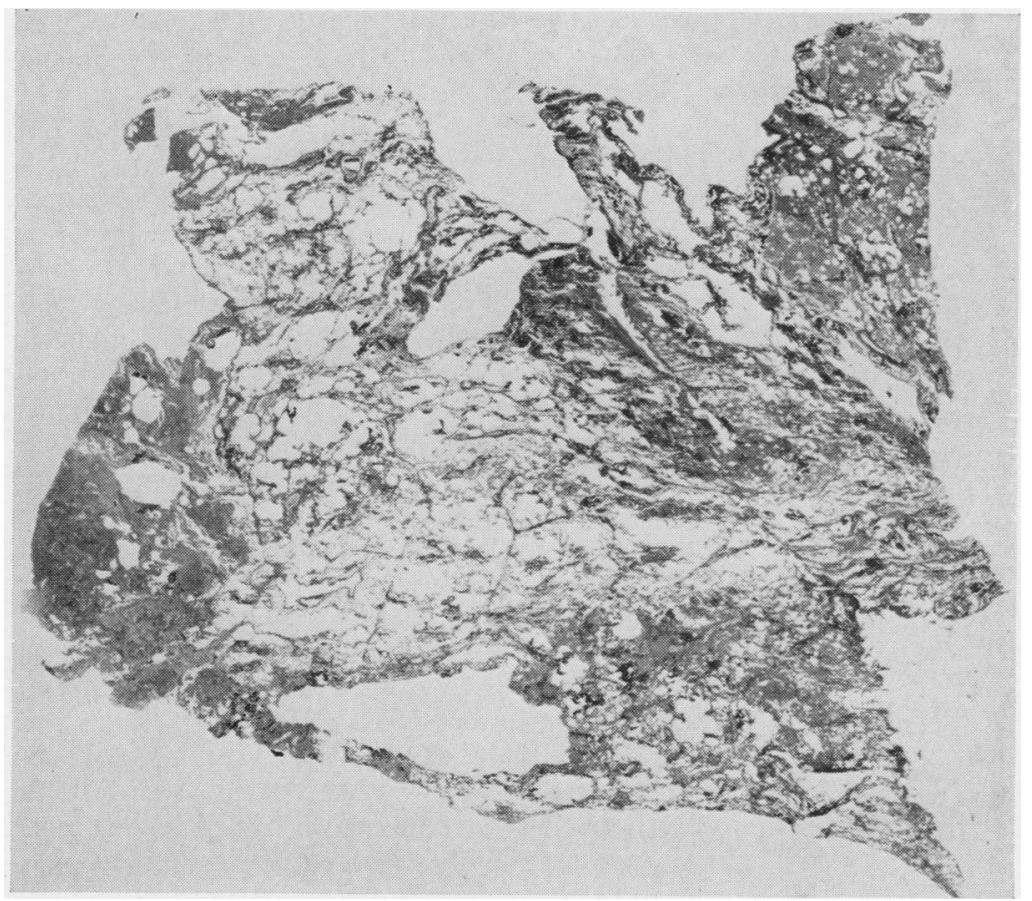

FIG. 12. Case 2. The lower lobe of the left lung showing areas of dense fibrous tissue, cystic air spaces, and dilated bronchioles: in the lower part and on the free borders are numerous xanthoma cells. Haematoxylin and eosin $\times 0.75$.

FIG. 13. Case 2. A frozen section of the lung demonstrating sudanophil lipid. Sudan III and haematoxylin $\times 150$.

FIG. 14. Case 2. Left lung showing cystic air spaces, with fibrous walls, and blood vessels with greatly thickened walls. Haematoxylin and eosin $\times 130$.

FIG. 12

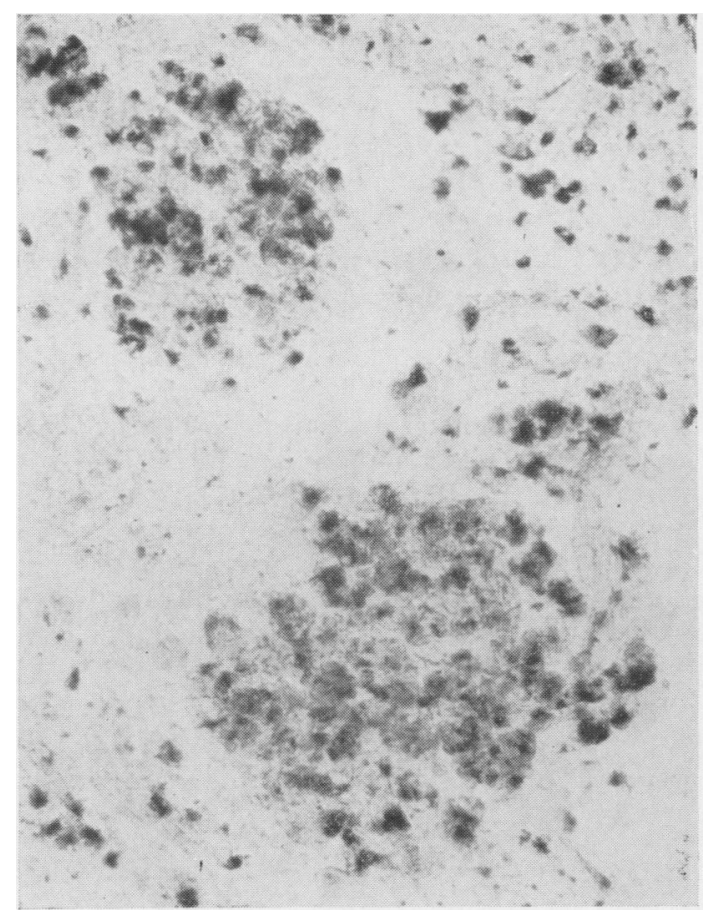

FIG. 13

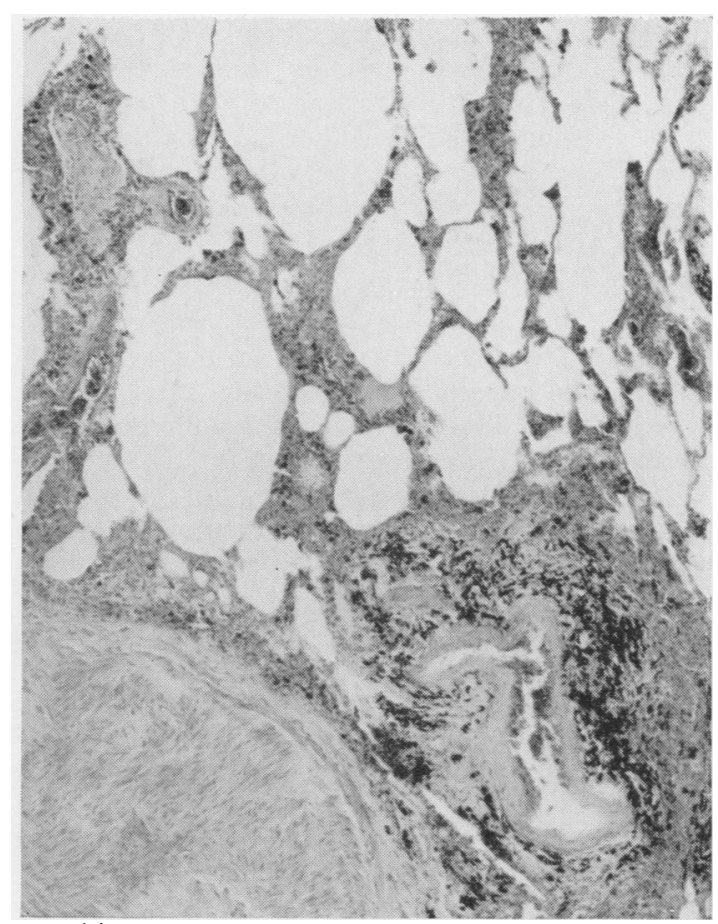

FIG. 14 


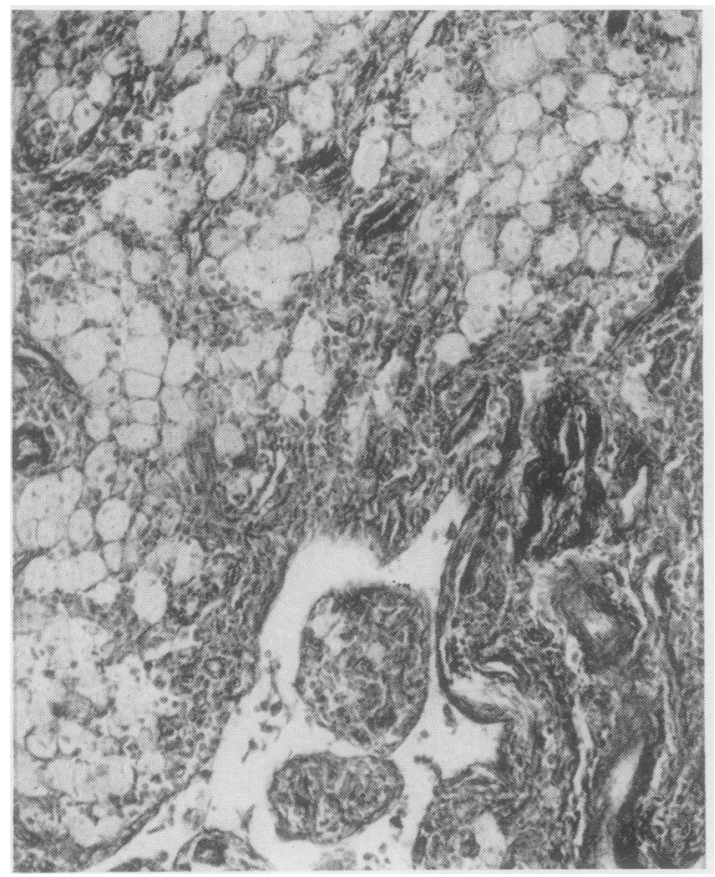

FIG. 15. Case 2. Groups of foam cells in a densely fibrous area at the base of the left lung. Azan $\times 130$.

tained chronic inflammatory exudate and red blood cells. The pulmonary arteries showed thickened walls and cellular infiltration of the adventitia which, in some instances, extended into the media or even to the intima. In the densely fibrous areas there was gross endarteritis obliterans.

\section{DISCUSSION}

In case 1 the disorder started, at the age of 29 years, with nausea and vomiting after meals: physical and radiological examination did not reveal any abnormality excepting weight loss.

Eight months later the patient had eye trouble, with pink discharge, and exophthalmos developed over the next two months. At this stage osteoclastic defects in membranous bones of the skull and orbits were shown radiologically but abnormal signs were not found on neurological examination. Blood chemistry, including total and free cholesterol, was normal.

Over the next 12 months exophthalmos became more marked, there was loss of visual acuity and central scotoma of the left eye: orbital decompression was performed but total blindness soon followed. Diabetes insipidus was not noted and pituitary pathology was not suspected at that time.
At the age of 33 years, his illness having lasted four years, the patient died suddenly of post-influenzal pneumonia.

Diabetes insipidus was not noted during life but the post-mortem finding of sclerosing xanthoma in the posterior lobe of the pituitary and xanthomatous deposits in the stalk favoured such a diagnosis. Thannhauser (1958) has suggested that xanthomatous involvement of the pituitary is sufficient anatomical evidence that one is dealing with diabetes insipidus. If such evidence is accepted the patient's condition fulfils the classical craniohypophyseal triad for the diagnosis of Hand-Schüller-Christian syndrome or one of its recognized variants (Henschen, 1931). The symptoms of diabetes insipidus would presumably have become obvious if life had not suddenly been terminated by pneumonia.

The gross appearances of the brain were normal but histological examination showed scattered foci of demyelination in the basal nuclei, mid and hind brain, the distribution being mainly perivascular and commonly in white matter. The disease process was mainly patchy myelin sheath degeneration but, in the substantia nigra and parts of the thalamic nuclei the substance had disintegrated. Some of these areas contained glial cells with pale cytoplasm and hyperchromatic nucleus: occasional mononuclear giant cells were present but not the compound granular corpuscles reported by Davison (1933) when describing a case of diabetes insipidus with areas of demyelination scattered throughout the fore, mid and hind brain.

Pathology in the pituitary comprised sclerosing xanthoma of the hypophysis and posterior lobe with fibrosis and foci of foam cells in the stalk. Changes in the tuber cinerium, as described by Davison (1933), or in the hypothalamus, as reported by Cavanagh and Russell (1954), were not seen. The association of pituitary pathology and diabetes insipidus in adults with xanthomatosis is exemplified by Hochstetter's case (Veit, 1922) where there was sclerosis of the posterior lobe: lipoid granulomatosis of the posterior lobe (Chester and Kugel, 1932); granulomatous lesions in neurohypophysis, pituitary stalk, and tuber cinereum in a case of generalized xanthomatosis (Chiari, 1931); atrophy and sclerosis of the pars posterior, occasional foam cells in the pars anterior, and changes in pituitary stalk of one case; fibrosis of pituitary stalk and pars posterior with some foam cells, in a second case (Cavanagh and Russell, 1954).

The retrobulbar optic nerves were surrounded, but not infiltrated, by xanthomatous masses; the consequent atrophic changes in the nerve substance were similar to those reported by Dietrich (1913) and in Snapper's case 1 (1943). Of the other cranial 
nerves, the fifth, seventh, and eighth showed areas of demyelination; there was also myelin loss to a lesser degree in the third and ninth. These changes may have resulted from compression following bony involvement of the skull base. Amongst reported necropsy findings the description of cranial nerve changes is usually confined to the optic nerves.

Involvement of the spinal dura mater was a feature of this case, the nodules being similar to those seen on the cerebral dura of adults and children by Veit (1922), Griffith (1924), Kyrklund (1926); Herzenberg (1928), Rowland (1928), Chiari (1931), and Cavanagh and Russell (1954). Xanthomatous infiltration of cord substance, as described by Feigin (1956), was not seen.

Diffuse demyelination in posterior and lateral white colums of the cord and ganglion cell degeneration in anterior horns and Clark's columns were present, the changes being most marked in the lumbosacral region: there was also herniation of cord substance into one of the lumbar posterior nerve roots. It appears probable that these changes resulted from epidural cord compression by the xanthomatous nodules as demonstrated by herniation of softened cord substance into a posterior rootlet into the lumbar region. This mechanism is more frequently associated with secondary epidural carcinoma.

The bony changes, confined to the head, were osteoclastic and locally destructive; there was no bony thickening as in osteosclerosis. The cellular lesion in the parietal bone was distinct from the more sclerotic pattern seen in the fronto-orbital region.

Eosinophilic granuloma almost replaced the thyroid cartilage leaving a thin, fragile shell; the overlying mucous membrane appeared normal. Xanthomatous involvement of the upper respiratory tract is frequently reported in the literature and, in cases recorded, the infiltration was confined to the mucous surfaces. Published examples of adult cases include those of Moxan (1873), Fagge (1873), and Pusey and Johnstone (1908). Finney (1931) reported a case showing deformity of the epiglottis and xanthomatous patches on the axilla and scrotum: Weidman and Schaffer (1937) found laryngeal involvement in a case of cutaneous xanthomatosis; Turner, Davidson, and White (1925) reported xanthomatous patches in the mouth, larynx, trachea, and bronchi of a patient who required tracheotomy for relief of laryngeal obstruction. Infiltration of cartilage appears to be an infrequent finding.

Another unusual feature was the massive, tumourlike infiltration of the right ventricular myocardium and chordae tendiniae: this suggested that rightheart failure would have become apparent if life had not been cut short by pneumonia. Published necropsy cases of adults and children generally report cardiac involvement as being limited to infiltration of subpericardial fat (Rowland, 1928; Freud, Grossman, and Dragutsky, 1941; Snapper, 1943; Thannhauser, 1958). Baggenstoss, Rosenberg, and Osterberg, 1940) described yellow streaking of the endocardium with slight muscle infiltration, and Chester (1930) reported three small granulomata in the heart muscle of one case. The two adult cases described by Cavanagh and Russell (1954) did not include cardiac lesions.

The peritoneal surfaces, including those of the pancreas, and the retroperitoneal tissues, are frequently infiltrated by xanthoma, both in children and adults (Henschen, 1931; Lane and Smith, 1939; Snapper, 1943; Thannhauser, 1958). Chester and Kugel (1932) described the pancreas of an adult as being firm and grey-yellow in colour but the parenchyma did not show abnormality. In the case reported here, in addition to numerous nodular masses on the surface, the parenchyma of the head and part of the body was largely replaced by xanthoma.

A further striking feature of case 1 was the massive constricting granuloma investing the whole of the kidneys and adrenals in one mass: a lesion of this type has not been described previously in any age group. Lipoid granuloma is commonly found in the peripelvic fat and occasionally infiltrating the renal cortical parenchyma (Veit, 1922; Ighenti, 1931; Freud et al., 1941; Teilum, 1942). Cavanagh and Russell (1954) described infiltration of peripelvic fat in one case and infiltration of renal cortex and fat around the calyces in another. Snapper's case 1 (1943) was unusual in that hydronephrosis had followed scarring of the renal pelvis due to lipoid granuloma. Chester (1930) described granulomatous infiltration of the adrenal cortex which was much greater than in the present case but mechanical compression, due to a surface layer of granuloma, was not present.

The wide variation of structure seen in case 1 covered the whole range of developmental stages characteristic of Hand-Schüller-Christian disease (Engelbreth-Holm, Teilum and Christensen, 1944; Teilum, 1942; Green and Farber, 1941 and 1942; Mallory, 1942). The thyroid cartilage, the most cellular lesion, contained numerous eosinophils and giant cells of the Touton type which suggested transition from the early reticulo-histiocytic phase to the granulation and early lipid accumulation stage. Reticulum cells, histiocytes, lymphocytes, and eosinophils were also found in the skull, heart, kidney, and adrenal gland lesions but in these areas there was also a variable amount of fibrous tissue. Xanthoma cells showed marked variation in distribution, in the extent of 
lipid accumulation and in the amount of fibrous tissue with which they were associated. In the pituitary stalk, xanthoma cells with large lipid accumulations predominated, whereas the lesion in the posterior lobe of the pituitary was largely sclerosed and devoid of sudanophilic material. The infiltrated heart muscle, the renal parenchyma, and the deposits on the spinal theca were rich in lipid whilst the lesions in the bone, pancreas, perinephric and periadrenal fat contained very little. Only occasionally were eosinophils seen in xanthomatous deposits. Histochemical examination confirmed that the lipid material contained cholesterol compounds.

The chemical values in Table I show correlation of chemical findings with histochemical methods: the deposits on the spinal dura were predominantly xanthomatous and contained the largest proportion of cholesterol. The heart, pancreas, adrenal glands, and kidneys showed intermediate values whilst the thyroid cartilage lesion, which contained fewest xanthoma cells, showed the lowest proportion of cholesterol.

TABLE I

\begin{tabular}{|c|c|c|c|c|c|c|}
\hline \multirow{3}{*}{$\begin{array}{l}\text { CHEN } \\
\text { Tissue } \\
\text { Examined }\end{array}$} & MICAL A & ANALYSIS & $S$ OF ORG & GANS AN & D TISSUE & \\
\hline & \multicolumn{2}{|c|}{$\begin{array}{l}\text { Total } \\
\text { Cholesterol }^{1}\end{array}$} & \multicolumn{2}{|c|}{$\begin{array}{l}\text { Total } \\
\text { Phospholipid' }\end{array}$} & \multicolumn{2}{|c|}{ Dry Weight ${ }^{2}$} \\
\hline & Tumour & Normal & Tumour & Normal & Tumour & Normal \\
\hline \multirow{10}{*}{$\begin{array}{l}\text { Spinal dura } \\
\text { Spinal dura } \\
\text { Kidney (left) } \\
\text { Kidney (right) } \\
\text { Kidney } \\
\text { Heart } \\
\text { Heart } \\
\text { Adrenal } \\
\text { Pancreas } \\
\text { Thyroid } \\
\text { cartilage } \\
\text { Thyroid } \\
\text { cartilage }\end{array}$} & $15 \cdot 6$ & \multirow{3}{*}{$1 \cdot 1$} & $1 \cdot 3$ & \multirow{3}{*}{$3 \cdot 1$} & $41 \cdot 7$ & \multirow{3}{*}{$38 \cdot 3$} \\
\hline & $4 \cdot 2$ & & $5 \cdot 7$ & & $65 \cdot 8$ & \\
\hline & t) $4 \cdot 1$ & & $7 \cdot 4$ & & 59.5 & \\
\hline & & \multirow[t]{2}{*}{0.7} & $2 \cdot 8$ & \multirow{5}{*}{$2 \cdot 8$} & & \multirow[t]{2}{*}{$70 \cdot 7$} \\
\hline & $7 \cdot 9$ & & $6 \cdot 4$ & & $50 \cdot 0$ & \\
\hline & & \multirow[t]{3}{*}{0.5} & & & & \multirow[t]{4}{*}{$70 \cdot 9$} \\
\hline & 6.9 & & $6 \cdot 6$ & & $71 \cdot 0$ & \\
\hline & $7 \cdot 3$ & & 0.4 & & $37 \cdot 7$ & \\
\hline & $1 \cdot 0$ & & 0.5 & & & \\
\hline & & $0 \cdot 8$ & & $0 \cdot 4$ & & \\
\hline
\end{tabular}

Case 2 is an example of xanthomatous granuloma, in a male aged 57 years, the lesion being confined to the lungs. There was no evidence of diabetes insipidus. In 1928, Rowland gave details of a 2-year-old child who died from pulmonary fibrosis secondary to xanthomatosis: since that time there have been several reports of pulmonary involvement in all age groups. Henschen (1931) mentions pulmonary lesions in nine out of 57 cases collected from the literature; of these three adults were examined at necropsy. Cavanagh and Russell (1954) found xanthomatous lesions of the lungs in both their cases: Livingstone, Lewis, Reid, and Jefferson (1964), in a paper on diffuse interstitial pulmonary fibrosis, mentioned two cases where the diagnosis of eosinophilic granuloma was made on biopsy material but details of the histology are not given.

The pathological changes described by Henschen (1931) and Cavanagh and Russell (1954) are similar to our own example: there is multifocal cellular proliferation, with deposition of collagen, which starts near the adventitia of blood vessels and in the subpleural and interlobular connective tissue. The proliferative cellular process is followed by atrophy of the parenchyma, the initial granulomatous pattern eventually being obliterated by a disorderly mass of scar tissue with cystic spaces, dilated bronchioles and thick-walled arteries being prominent in the alveolar tissue. The final appearances correspond to pulmonary fibrosis of grade 4 or 5 as described by Livingstone et al. (1964) but the histological appearances of the cystic spaces differ from that described in 'honeycomb lung' by Parkinson (1949) and Oswald and Parkinson (1949). The cystic changes in this case was probably related to the longstanding chronic xanthoma and to the severe cough and dyspnoea which the patient suffered during the last few months of his life.

The association of xanthomatous granuloma and carcinoma in case 2 is unusual. Weidman and Schaffer (1937) discussed the question of a causal relationship at some length but the connexion appears tenuous, certainly in the case described here.

It is now generally accepted that Hand-SchüllerChristian disease is a phase in a generalized disorder of the reticuloendothelial system, or a reticuloendotheliosis with secondary cholesterol infiltrations producing xanthomatous areas. It is no longer a distinct and separate disease but part of a group which includes Letterer-Siwe disease and eosinophilic granuloma of the bone. They are all facets of a common pathological disorder (Green and Farber, 1941 ; Mallory, 1942).

Formerly Hand-Schüller-Christian disease was regarded as a primary disturbance of lipid metabolism or a normocholesterolaemic xanthomatosis (Thannhauser and Magendantz, 1938). This concept has been abandoned (Mallory, 1942) and the presence of cholesterol in the lesions is regarded as a secondary infiltration. While accepting the deposition of lipid in the xanthoma as a secondary infiltration, Cavanagh and Russell (1954) explain this infiltration as an excessive breakdown or phagocytosis of the normal tissues by macrophages, thus representing an exaggeration of their normal potentialities. In the later stages of the disease macrophages tend to break down and release this lipid into the tissues causing diffuse fibrosis in the whole lesion. A further possibility is that the disease process prevents the reticuloendothelial cells from transmitting lipid material with consequent accumulation: it has been shown (Halpern, Benacerraf, 
and Delafresnaye, 1957) that one of the normal functions of the reticuloendothelial system is the transport of lipids, lipoproteins, and cholesterol.

The evolution of the disease is relatively slow. In the first case presented here it was four years and in that of Chester and Kugel (1932) it was as long as eight years.

We are indebted to Dr. L. J. Rubinstein for reviewing the manuscript and making helpful suggestions; to Mr. G. K. Tutton for the orbital biopsies in case 1; to Mr. G. R. A. Padmore for the chemical analyses: to Messrs J. H. Wilkinson and J. A. Urquhart for preparing numerous sections and to Miss M. H. Fernhead for clerical help.

\section{REFERENCES}

Baggenstoss, A. H., Rosenberg, E. F., and Osterberg, A. E. (1940). Arch. Path., 29, 420.

Cavanagh, J. B., and Russell, D. S. (1954). J. Path. Bact., 68, 165.

Chester, W. (1930). Virchows Arch. path. Anat., 279, 561.

- and Kugel, V. H. (1932). Arch.Path., 14, 595.

Chiari, H. (1931). Ergebn. allg. Path. path. Anat., 24, 396.

Davison, C. (1933). Arch. Neurol. Psychiat. (Chig.), 30, 75.

Dietrich, A. (1913). Virchows Arch. path. Anat., 212, 119.

Engelbreth-Holm, J., Teilum, G., and Christensen, E. (1944). Acta med. scand., 118, 292.

Fagge, C. H. (1873). Trans. path. Soc. Lond., 24, 242.

Feigin, I. (1956). J. Neuropath. exp. Neurol., 15, 400.

Finney, W. P. (1931). Proc. Mayo Clin., 6, 667.
Freud, P., Grossman, L., and Dragutsky, D. (1941). Amer. J. Dis. Child., 62, 776.

Gomori, G. (1942). J. Lab. clin. Med., $27,955$.

Green, W. T., and Farber, S. (1941) New Engl. J. Med., 224, 832.

- - - (1942). J. Bone Jt Surg., $24,499$.

Griffith, F., (1924) Cited by Davison, C. (1933). Arch. Neurol. Psychiat. (Chig.), 30, 75.

Halpern, B. N., Benacerraf, B., and Delafresnaye, J. F. (1957). Physiopathology of the Reticulo-endothelial System. Blackwell, Oxford.

Henschen, F. (1931). Acta paediat. (Uppsala), 12, suppl. 6.

Herzenberg, H. (1928). Virchows Arch. path. Anat., 269, 614.

Ighenti, W. K. (1931). Ibid., 282, 585.

Kyrklund, R. (1926). Z. Kinderheilk., 41, 56.

Lane, C. W., and Smith, M. G. (1939). Arch. Derm. Syph. (Chic.), $39,617$.

Livingstone, J. L., Lewis, J. G., Reid, L., and Jefferson, K., (1964). Quart.J. Med., 33, 71.

Mallory, T. B. (1942). New Engl. J. Med., 227, 955.

Moxan, W. (1873). Trans. path. Soc. Lond., 24, 129.

Oswald, N., and Parkinson T. (1949). Quart. J. Med., n.s., 18, 1.

Parkinson, T. (1949). Brit. med.J., 1, 1029.

Pearson, S., Stern, S., and McGavack, T. H. (1953). Analyt. Chem. $25,813$.

Pusey, W. A., and Johnstone, O. P. (1908). J. cutan. Dis., 26, 552.

Rowland, R. S. (1928). Arch. intern. Med., 42, 611.

Snapper, I. (1943). Medical Clinics on Bone Diseases. Interscience, New York.

Teilum, G. (1942). Beitr. path. Anat., 106, 460.

Thannhauser, S. J. (1958). Lipidoses: Diseases of the Intra Cellular Lipid Metabolism., 3rd ed. Grune and Stratton, New York.

- , and Magendantz, H. (1938). Ann. intern. Med., 11, 1662

Turner, A. L., Davidson, J., and White, A. C. (1925). Edin. med. J., $32,153$.

Veit, B. (1922). Frankfurt Z. Path., 28, 1

Weidman, F. D., and Schaffer, H. W. (1937). Arch. Derm. Syph. (Chic.), 35, 767. 